\title{
Multi-Band and Multi-Parameter Reconfigurable Slotted Patch Antenna with Embedded Biasing Network
}

\author{
Manoj Kumar Garg*1 ${ }^{1}$ Jasmine Saini ${ }^{2}$ \\ Department of Electronics and communication \\ Jaypee Institute of Information and Technology Noida, Uttar Pradesh, India ${ }^{1,2}$
}

\begin{abstract}
RF PIN diodes are used to achieve reconfigurability in frequency, polarization, and radiation pattern. The antenna can be used in different bands by controlling ON and OFF states of two PIN diodes using the embedded biasing network (EBN). The antenna can be used for ultra-wideband (UWB) applications $(1.0 \mathrm{GHz}$ to $15.2 \mathrm{GHz})$ with a resonant frequency of $9.2 \mathrm{GHz}$. Besides ultra-wideband, it can also be switched to other bands $(\mathrm{C}, \mathrm{X}$, and $\mathrm{Ku})$ with different operating frequencies $(5.75 \mathrm{GHz}, 12.3 \mathrm{GHz}$, and $15.5 \mathrm{GHz})$ at other biasing combinations. With this type of antenna, Linear and Circular polarization are achievable. The radiation pattern reconfigurable behavior in the vertical plane has also been achieved. Single Design of the proposed antenna is optimized for the multi-band and multi-parameter reconfigurability applications.
\end{abstract}

Keywords-Multi-band; Multi-parameter reconfigurability; $E B N ; U W B ; P I N$ diode

\section{INTRODUCTION}

Ultra-wideband antenna design with multiple notches using a finite ground plane approach and the hierarchy process method was reported by Padmavathy et al. [1] and Zehforoosh [2]. Recently, multi-parameter reconfigurable antennas have gained considerable attention in the design of modern communication systems [3]. Earlier papers focused on singleparameter reconfigurability, but so far very little work has been done on multi-parameter reconfigurable behavior. The dependency of antenna characteristics i.e. frequency bandwidth, return loss, gain, etc. makes the design of the multi reconfigurable antenna a complex task. A frequencyreconfigurable microstrip patch slot antenna at nine different frequency bands between 1.98 and $3.59 \mathrm{GHz}$ was proposed by Huda A et al. [4]. A frequency reconfigurable multiband antenna with the embedded biasing network for microwave access, mobile and wireless network was proposed by Adisak Romputtal et al. [5]. For wideband applications, slot antennas are very popular. Hui $\mathrm{Li}$ et al. have proposed a simple compact reconfigurable slot antenna with a very wide tuning range [6]. A polarization and radiation pattern reconfigurable antenna for different applications was presented by $\mathrm{Zi}$-Xian et al.[7] and J. Constantine [8].The large gain of $3.19 \mathrm{dBi}$, high bandwidth of 162.910 and patch size reduction of $56.5 \%$ have been achieved in a single layer hexagonal patch antenna by using two triangles and one rectangular slot on patch [9]. The monopole antenna with $\mathrm{T}$ slot on the partial ground plane and the LC equivalent model of the same structure were simulated using ADS platform. The simulated results of the structure and its electrical equivalent model were found to be in good agreement with each other. [10]. A UWB of 3.1 to $10.6 \mathrm{GHz}$ with a notched frequency band was achieved by using an arcshaped slot on a circular patch [11]. A UWB antenna with dual band-notched characteristics in the WiMAX/WLAN bands by etching two $\mathrm{C}$ shaped slots in the rectangular patch was proposed [12]. A comparative study of the rectangular patch antenna on Terahertz frequency with and without superstrate has been done and achieved the large matching bandwidth and gain $(22.47 \%, 10.43 \mathrm{dBi})$ [13].

In the present scenario, reconfigurable antennas play a significant role in the modern communication system and provide multifunction abilities to perform multiple tasks. By integrated active components with a patch antenna, the reconfigurable behavior can be achieved. This paper has implemented a viable ultra-wideband microstrip patch antenna with reconfigurable behavior in frequency, radiation pattern and polarization. The multi-parameter reconfigurable characteristics of the proposed antenna can be achieved by using different switching combinations of two PIN diodes. The first PIN diode is integrated into the slot of microstrip patch and the second PIN diode is integrated between two partial ground planes. The switching of these two PIN diodes is achieved by suitable biasing circuits. In this design, we have used a rectangular patch with two corner arcs and two slits. This antenna enables us to use in any of the three bands $\mathrm{C}, \mathrm{X}$, and $\mathrm{Ku}$ depending upon the requirement. The antenna also provides us the freedom to operate either in linear or circular polarization such as in WLAN and VSAT applications. The proposed antenna is capable to transmit/receive in any of the four directions, $\varphi=0^{\circ}, 90^{\circ}, 180^{\circ}$, and $270^{\circ}$ as per the requirement.

\section{ANTENNA DESIGN AND FORMULATION}

The design formulation is divided into two parts. The first part discusses the design of an antenna. The second part shows how multi reconfigurable behavior is achieved. In this work, two designs of antennas are proposed. The patch design for an antenna is shown in Fig. 1(a). In the first design, the antenna is presented with the single partial ground as shown in Fig. 1(b) and the second design are presented with two partial grounds as shown in Fig. 1(c).

*Corredponding Authors 


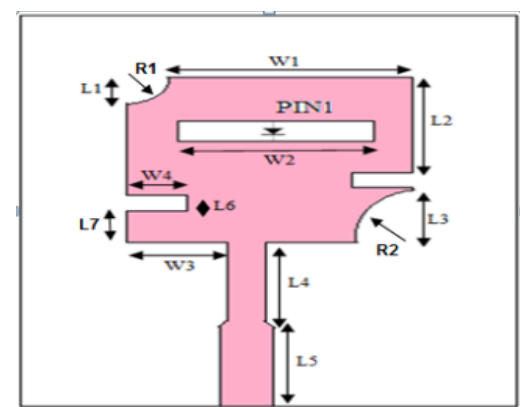

(a)

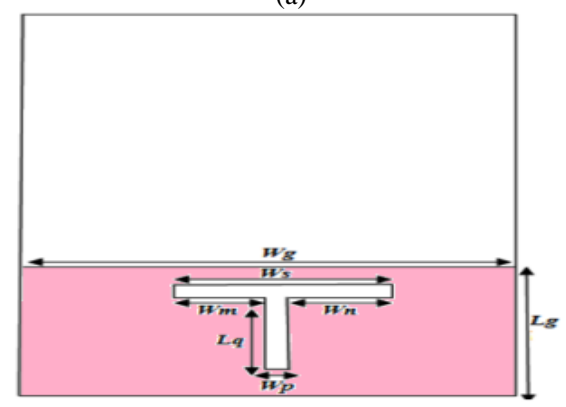

(b)

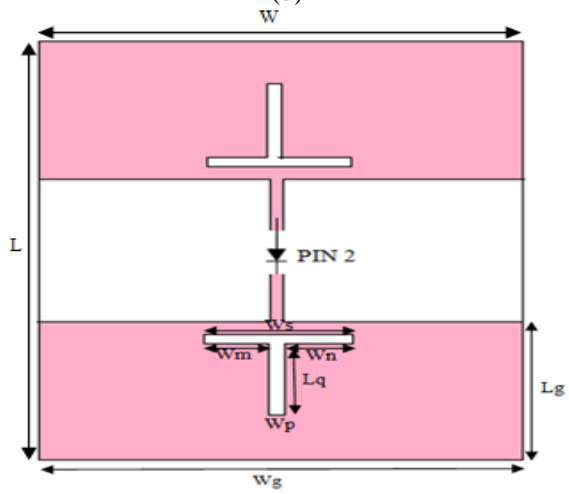

(c)

Fig. 1. Antenna Geometry (a) Patch (b) Single Partial Ground (c) Two Partial Ground.

In the designing part, a number of techniques like corner truncation, cutting a rectangular slot and side slit on the patch are used to archive a large bandwidth. The location of slots and slits is optimized for achieving maximum bandwidth. A T slot is used on partial ground of antenna as shown in Fig. 1(b). This $\mathrm{T}$ slot provides good impedance matching between the antenna and coaxial cable so that maximum power can be transferred to the antenna. For ultra-wideband applications, a rectangular slot is designed on the patch to enhance the bandwidth of the proposed antenna. Without slot, antenna (with the single partial ground) resonates at $10 \mathrm{GHz}$ frequency only and when rectangular slot is taken on the patch, a second higher mode at $15 \mathrm{GHz}$ is obtained, as evident from Fig. 2.

According to the size of the slot, the equivalent inductance and capacitance of slot, as well as resonating frequency of higher mode, can be calculated by the formulas given in equation (1) [14]. By varying the length and width of the slot, a different higher mode of different resonant frequency is generated and with the help of these higher modes, the bandwidth of the antenna can be enhanced.

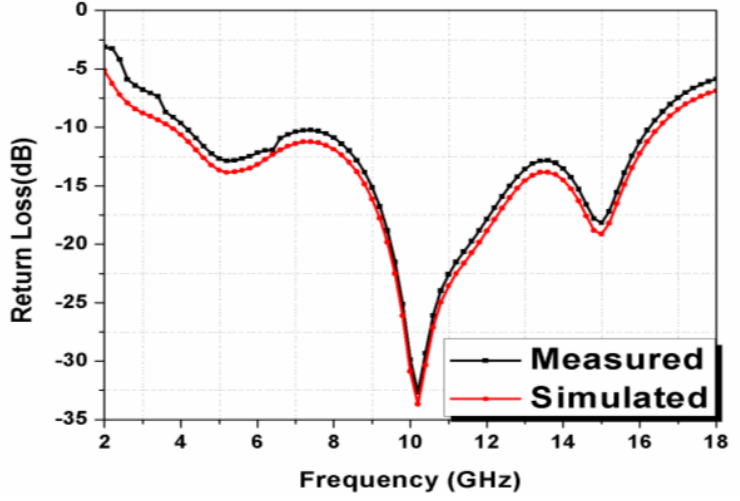

Fig. 2. Measured and Simulated Return Loss of Single Partial Ground Antenna with a Rectangular Slot on Patch.

Ls $=\frac{h \mu o \pi}{8}\left(\frac{1}{w}\right)^{2}$, Cs $=\frac{\varepsilon \circ \varepsilon r A}{D}$ and $\mathrm{fr}=\frac{1}{2 \pi \sqrt{\mathrm{LSC}}}$

Where

$\mathrm{Ls}=$ Equivalent Inductance of the slot;

$\mathrm{Cs}=$ Equivalent capacitance;

$$
\begin{aligned}
& \text { l= length of slot; } \\
& \text { w= width of slot; } \\
& \mathrm{fr}=\text { Resonate frequency. }
\end{aligned}
$$

The present design is usable for RT Duriod 5880 with a thickness of $1.6 \mathrm{~mm}$, the relative permittivity of 2.2 and dielectric loss tangent of 0.0009 . The length and width of the substrate are selected as $36 \mathrm{~mm} \times 34 \mathrm{~mm}$. The calculated patch size is of $18 \mathrm{~mm} \times 11.7 \mathrm{~mm}$, where two corner arcs and two slits are cut. For Proper impedance matching a two-step, the microstrip feed line is used. The dimensions of the proposed antenna are tabulated in Table I.

For achieving the reconfigurable behavior of the proposed antenna, another partial ground is introduced at the ground plane with the same dimensions. A PIN diode is used to connect these two partial grounds as shown in Fig. 1(c). Another PIN diode is embedded between the slots on the patch as shown in Fig. 1(a). These two PIN diodes (SMP1345079LF, Ls=7nH SC-79) are used to control frequency, polarization, and radiation pattern reconfigurable behavior of the proposed antenna. Fig. 3 shows an equivalent circuit of PIN diode in forward and reverse bias. When the forward biasing voltage of $0.89 \mathrm{~V}$ and above is supplied, the PIN diode turns on and behaves as a short circuit with a series resistance of $1.5 \Omega$. Without biasing voltage the PIN diode acts as an open circuit and has the capacitance of $0.15 \mathrm{pF}[3]$.

TABLE. I. DimENSIONS OF THE PROPOSED ANTENNA (MM)

\begin{tabular}{|l|l|l|l|l|l|}
\hline $\mathbf{L}_{\mathbf{1}}$ & $3 \mathrm{~mm}$ & $\mathbf{L}_{\mathbf{7}}$ & $2 \mathrm{~mm}$ & $\mathbf{W}_{\mathbf{4}}$ & $2 \mathrm{~mm}$ \\
\hline $\mathbf{L}_{\mathbf{2}}$ & $7.9 \mathrm{~mm}$ & $\mathbf{L}_{\mathbf{q}}$ & $5 \mathrm{~mm}$ & $\mathbf{W}_{\mathbf{g}}$ & $36 \mathrm{~mm}$ \\
\hline $\mathbf{L}_{\mathbf{3}}$ & $3 \mathrm{~mm}$ & $\mathbf{L}_{\mathbf{g}}$ & $10 \mathrm{~mm}$ & $\mathbf{W}_{\mathbf{m}}$ & $2.25 \mathrm{~mm}$ \\
\hline $\mathbf{L}_{\mathbf{4}}$ & $6 \mathrm{~mm}$ & $\mathbf{W}_{\mathbf{1}}$ & $15 \mathrm{~mm}$ & $\mathbf{W}_{\mathbf{n}}$ & $2.25 \mathrm{~mm}$ \\
\hline $\mathbf{L}_{\mathbf{5}}$ & $5.15 \mathrm{~mm}$ & $\mathbf{W}_{\mathbf{2}}$ & $10 \mathrm{~mm}$ & $\mathbf{W}_{\mathbf{p}}$ & $0.5 \mathrm{~mm}$ \\
\hline $\mathbf{L}_{\mathbf{6}}$ & $0.8 \mathrm{~mm}$ & $\mathbf{W}_{\mathbf{3}}$ & $36 \mathrm{~mm}$ & $\mathbf{R}_{\mathbf{1}}=\mathbf{R}_{\mathbf{2}}$ & $\mathbf{3 m m}$ \\
\hline
\end{tabular}




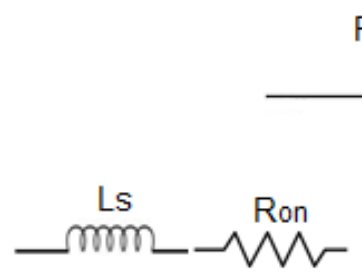

forward bias

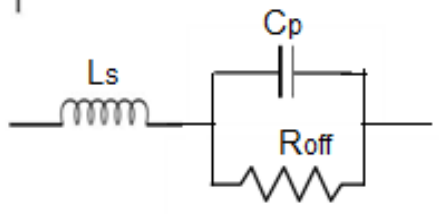

reverse bias
Fig. 3. Equivalent Circuit of PIN Diode (SMP1345-079LF).

\section{EMBEDDED BIASING NETWORK}

A biasing circuit for switching off the PIN diode is shown in Fig. 4. In this biasing circuit, two blocking capacitors of value $0.1 \mu \mathrm{F}$ and two RF coils of value $6.8 \mathrm{nH}$ are used. The blocking capacitor prevents microstrip antenna with the DC bias voltage given to the PIN diode and passes AC (high frequency) signal through the diode. RF coil allows DC current and prevents the microcontroller board from AC (high frequency) signal. Instead of using DC power supply along with various lumped components for switching PIN diodes, a microcontroller-controlled embedded biasing network (EBN) is used with the antenna to regulate the PIN diode switching and it overcomes the various problems like cost, weight, and complexity as shown in Fig. 5 [15]. The ON and OFF timing of a PIN diode can be controlled by using a microcontroller (ATMEGA 2560).

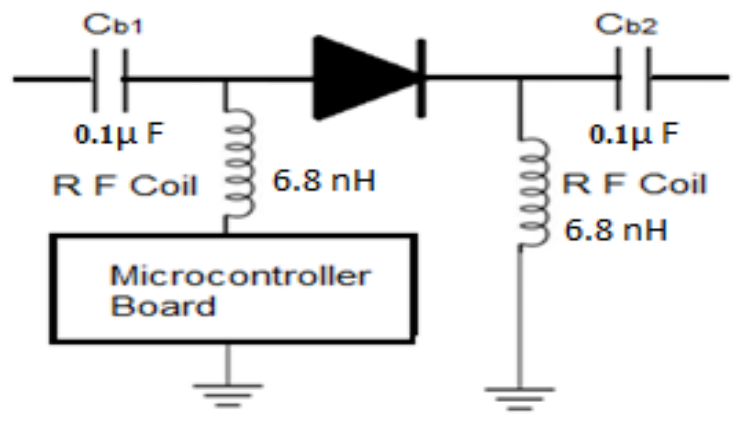

Fig. 4. Biasing Circuit for Switching of a PIN Diode.

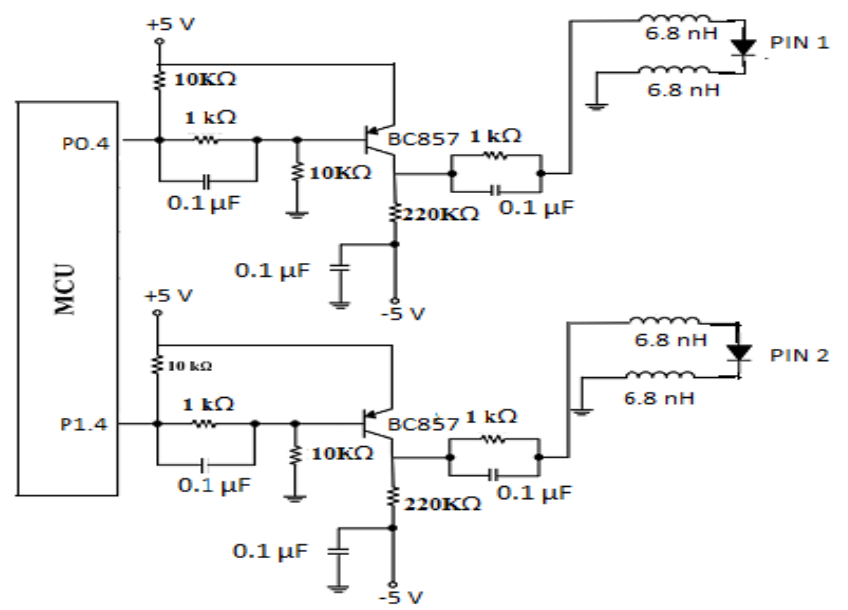

Fig. 5. Embedded Biasing Network using ATMEGA 2560 Microcontroller.

\section{RESULTS AND DISCUSSION}

For ultra-wideband applications, a single partial ground patch antenna is fabricated at a frequency of $10 \mathrm{GHz}$. It provides a large bandwidth from $3.5 \mathrm{GHz}$ to $16 \mathrm{GHz}$ as shown in Fig. 2. The experimental and simulated results are in good agreement with each other, and hence, the proposed antenna model with a single partial ground plane is recommended for the ultra-wideband application. For achieving multiple reconfigurable behaviors another microstrip patch antenna with two partial grounds is designed and fabricated as shown in Fig. 6(b). By using two PIN diodes, the reconfigurable behavior of the antenna is achieved. The simulated and measured return loss of the proposed antenna with two partial ground plane $\mathrm{s}$ at different switching positions of two diodes is shown in Fig. 7. It is clearly evident that the antenna provides different resonant frequency and return loss according to different switching combinations of two PIN diodes. A frequency shift of $1 \mathrm{GHz}$ to the left side has been observed in the measured return loss graph of fabricated antenna. Fig. 7(a) shows the return loss graph of the antenna model when both diodes (PIN 1 and PIN 2) remain OFF and in this situation; the antenna provides UWB similar to a single partial ground antenna. The simulated and experimental results of the antenna model using different switching combinations of PIN diodes are obtained and tabulated in Table II.

Table III tabulates the axial ratio at different switching combinations of PIN diodes. In position 1 (when both PIN diodes are OFF) and in position 2 (when PIN 1 is ON and PIN 2 is OFF) the antenna attains circular polarization as the axial ratio is nearly unity. In position 3 (when PIN 1 is OFF and PIN 2 is ON) and in position 4 (when both PIN diodes are $\mathrm{ON}$ ) antenna shows linear polarization because the axial ratio is far greater than 1 . The simulated and measured radiation patterns of the antenna models at all four combinations are shown in Fig. 8.

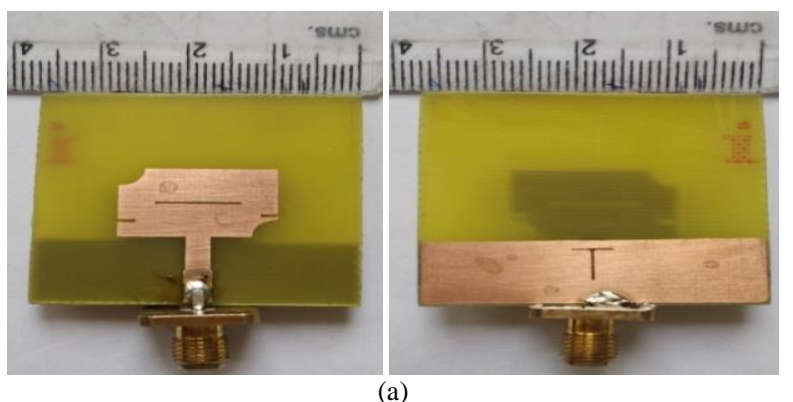

(a)

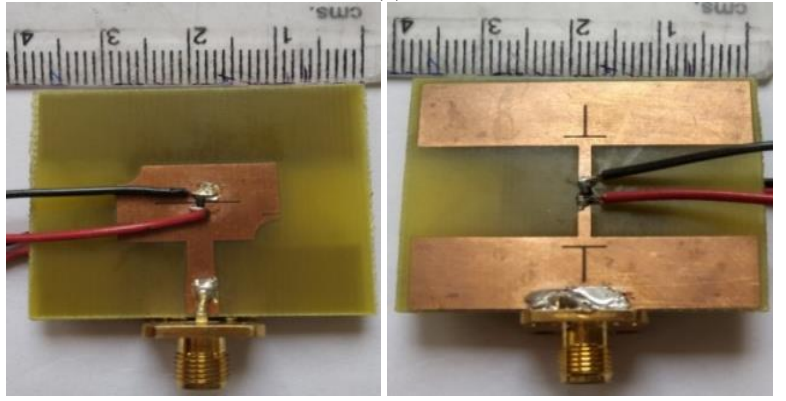

(b)

Fig. 6. Fabricated Antenna (a) with the Single Partial Ground (b) with Two Partial Ground. 


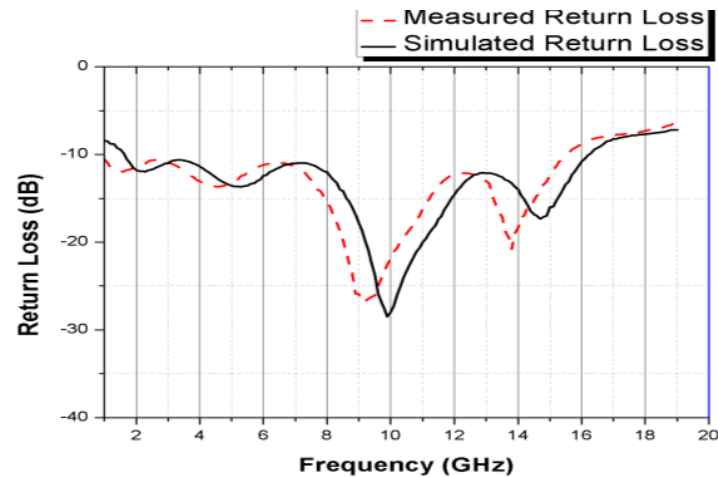

(a)

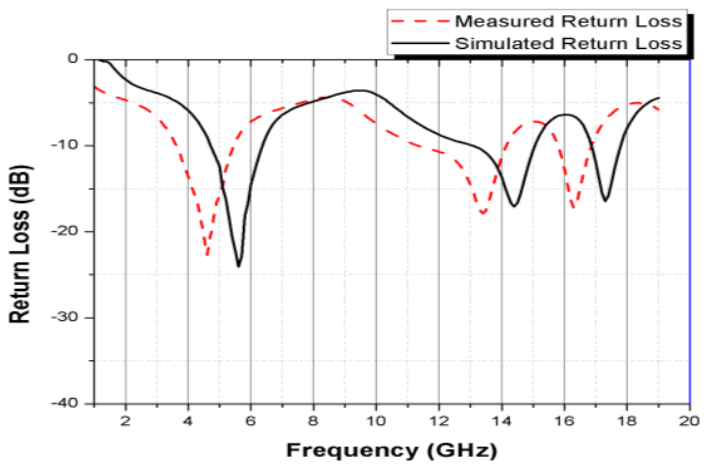

(c)

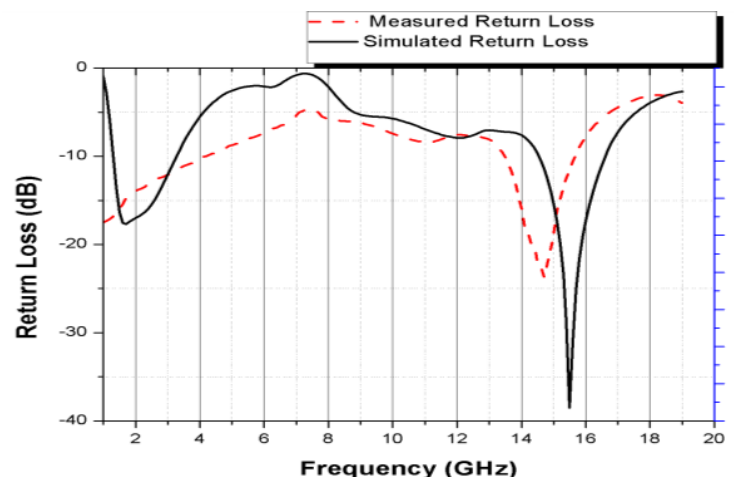

(b)

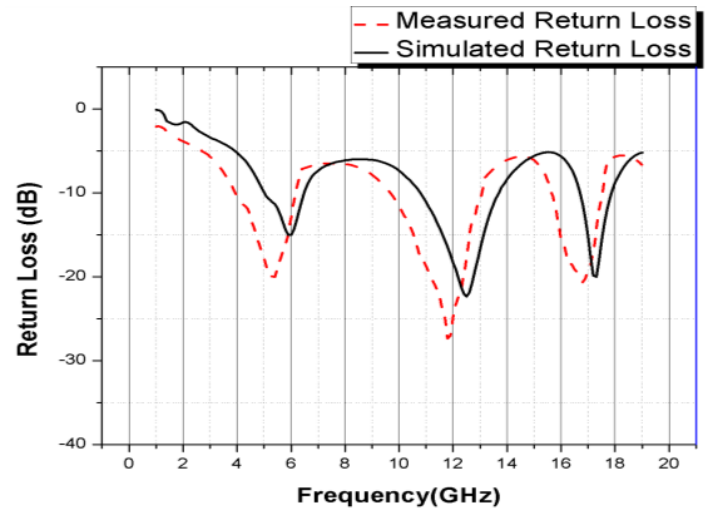

(d)

Fig. 7. Return Loss at different Switching Positions of PIN Diodes. (a) PIN 1 OFF and PIN 2 OFF (b) PIN 1 ON and PIN 2 OFF (c) PIN 1 OFF and PIN 2 ON (d) PIN 1 ON and PIN 2 ON.

TABLE. II. COMPARATIVE PARAMETRIC STUdy ON DifFERENT SWITCHING COMBINATIONS OF Pin DiOdeS

\begin{tabular}{|l|l|l|l|l|l|l|l|l|}
\hline \multicolumn{2}{|l|}{ Switching } & \multicolumn{2}{l|}{ Resonant frequency $(\mathbf{G H z})$} & \multicolumn{2}{l|}{ Band $(\mathbf{G H z})$} & \multicolumn{2}{l|}{ Return Loss (dB) } \\
\hline PIN 1 & PIN 2 & Simulated & Measured & Simulated & Measured & \multicolumn{2}{l|}{ Simulated } & Measured \\
\hline OFF & OFF & 9.9 & 9.2 & $1.6-16$ & $1.0-15.2$ & -28 & -26 & UWB \\
\hline ON & OFF & 15.5 & 14.3 & $14.7-16.6$ & $12.7-15.4$ & -38.8 & -24 & Ku \\
\hline OFF & ON & 5.75 & 4.5 & $4.6-6.3$ & $3.6-5.5$ & -24.5 & -23 & C \\
\hline ON & ON & 12.3 & 11.9 & $10.8-13.6$ & $9.4-13.0$ & -22 & -27 \\
\hline
\end{tabular}

TABLE. III. The Axial Ratio AT DifFERENT SWitching Combinations of PIN Diodes

\begin{tabular}{|l|l|l|l|l|}
\hline S. No & PIN 1 & PIN 2 & Axial Ratio (dB) & Type of polarization \\
\hline $\mathbf{1}$ & OFF & OFF & 1.5 & Circular \\
\hline $\mathbf{2}$ & ON & OFF & 1.3 & Circular \\
\hline $\mathbf{3}$ & OFF & ON & 16.5 & Linear \\
\hline $\mathbf{4}$ & ON & ON & 20 & Linear \\
\hline
\end{tabular}

The radiation patterns are plotted in the elevation plane i.e at $\varphi=0^{\circ}$. In the first case (PIN 1 OFF and PIN 2 OFF) this antenna radiates in a vertical direction from $\theta=-40^{\circ}$ to $\theta=$ $+40^{\circ}$ as shown in Fig. 8(a). In second case (PIN 1 ON and PIN $2 \mathrm{OFF})$ it radiates in horizontal direction i.e. $\theta=-70^{\circ}$ to $\theta=-$ $110^{\circ}$ shown in Fig. 8(b).

In the third case (PIN 1 OFF and PIN 2 ON) it radiates in the vertical direction (opposite to the direction of the first case) from $\theta=-140^{\circ}$ to $\theta=+140^{\circ}$ as shown in Fig. 8(c).
In the fourth case (PIN $1 \mathrm{ON}$ and PIN $2 \mathrm{ON}$ ) this antenna radiates in the horizontal direction and this time opposite to the direction of to the second case that is it is radiating from $60^{\circ}$ to $120^{\circ}$ as shown in Fig. 8(d). By observing radiation patterns on different switching combinations it is evident that the antenna model is radiating along with different directions. Thus reconfigurable behavior of the proposed antenna in radiation pattern is achieved. 


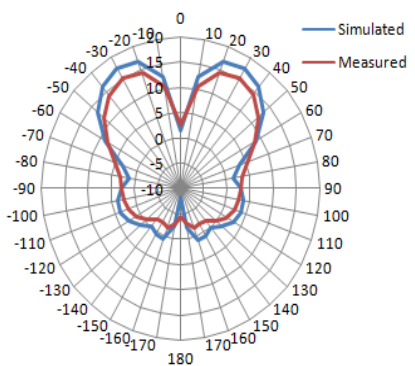

(a)

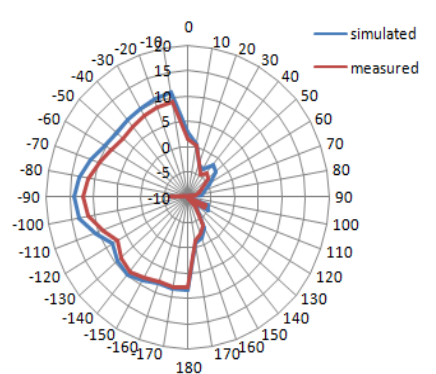

(b)

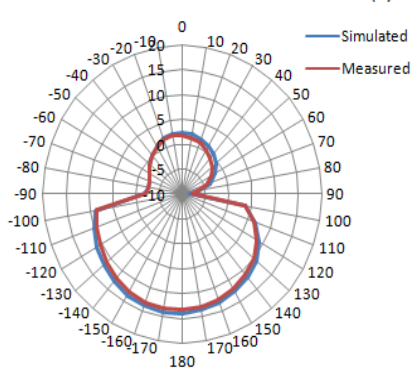

(c)

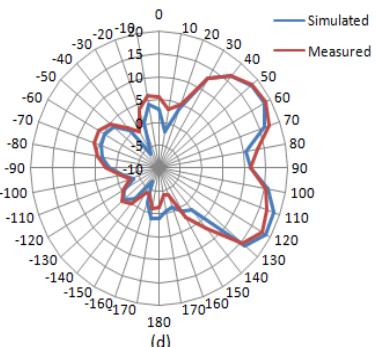

(d)
Fig. 8. Radiation Pattern at different Switching Positions of PIN Diodes (a) PIN 1 OFF \& PIN 2 OFF, (b) PIN 1 ON \& PIN 2 OFF, (c) PIN 1 OFF \& PIN 2 ON, (d) PIN 1 ON \& PIN 2 ON.

\section{CONCLUSION}

It is observed that the proposed antenna model provides not only multi-band operation but also executes as a multiparameter reconfigurable antenna with a high gain of $10 \mathrm{~dB}$. The proposed antenna model provides different frequency bands $(\mathrm{C}, \mathrm{X}$, and $\mathrm{Ku})$ with different switching combinations of two PIN diodes. The radiation pattern of the proposed antenna can be switched in multiple directions by controlling $\mathrm{ON}$ and OFF positions of both diodes. The proposed antenna model will be very useful in commercial and military applications because the proposed antenna provides the freedom to choose the different types of applications.

\section{ACKNOWLEDGMENT}

Authors would like to thank the Department of Electronics and Communication Engineering, JIIT Noida and AIT New Delhi for providing the necessary facility to carry out the measurement of the antenna. We thank Manoj Vishwakarma, Assistant Professor IEC College of Engineering and Technology for comments that greatly improved the manuscript.

\section{REFERENCES}

[1] A.P Padmavathy and M.Ganesh Madhan, "An improved UWB patch antenna design using multiple notches and finite ground plane," Journal of Microwaves, Optoelectronics, and Electromagnetic Applications, Vol.14, No1, pp.133-142, June 2015.

[2] Y. Zehforoosh and M. Mohammadifar, "Designing four notched bands microstrip antenna for UBW applications assessed by analytic hierarchy process method," Journal of Microwaves, Optoelectronics and Electromagnetic Applications, Vol. 16, No 3, pp. 765-776, September 2017.

[3] K.Chung, Y. Nam and T. Yun, "Reconfigurable microstrip patch antenna with frequency and polarization-diversity functions," Microwave Optical Technology Letters, Vol. 47, No .6, pp. 605-607, 2005.

[4] Huda A. Majid, "Frequency-Reconfigurable Microstrip Patch-Slot Antenna," IEEE Antennas And Wireless Propagation Letters, Vol. 12, 2013.

[5] Adisak Romputtal, Chuwong Phongcharoenpanich, "Frequency reconfigurable multiband antenna with the embedded biasing network," IET Microw. Antennas Propag., Vol. 11, pp. 1369-1378, 2017.

[6] Hui Li, Jiang Xiong, Yufeng Yu, and Sailing He, "A Simple Compact Reconfigurable Slot Antenna With a Very Wide Tuning Range,” IEEE Transactions on Antennas and Propagation, Vol. 58, No. 11, November 2010.

[7] Zi-Xian Yang and Hong-Chun Yang, "Bandwidth Enhancement of a Polarization-Reconfigurable Patch Antenna With Stair-Slots on the Ground," IEEE Antennas and Wireless propagation letters, Vol. 13, 2014.

[8] J. costantine, RKanj, Z. Ghorayeb, T. Ai Bahar, Y. Itani, Y Tawk and C.G. Chistodoulou. "A radiation pattern reconfigurable antenna for WLAN access,". USNC-URSI NRSM. IEEE Xplore 21 March 2016.

[9] S. Jana, Bipadtaran Sinhamahapatra, Sudeshna Dey, Arnab Das, Bipa Datta, Moumita Mukherjee, and Samiran Chatterjee, "Single-layer monopole hexagonal microstrip patch antenna for satellite television," International Journal of Soft Computing and Engineering, pp. 22312307, 2013.

[10] Manoj Garg, Jasmine Saini, Sandeep Kumar, B.K.Kanaujia and Gunjan Mittal, "Extracted LC Model of Monopole antenna with-slot for UWB application," IEEE Xplore, pp.79-82, July 2017.

[11] Schantz, H. G., and G. P. Wolenec, "Ultra-wideband antenna having frequency selectivity," U.S. Patent No. 6774859B2, August 2004.

[12] Chu, Q. X. and Yang Y. Y., "A compact ultra-wideband antenna with 3.4/5.5GHz dual band-notched characteristics," IEEE Trans. Antennas Propag, Vol. 56, No.12, pp.3637-3744, December 2008.

[13] M. Younis, Achraf Jaoujal, M. H. Diallo Yaccoub, Ahmed El Moussaoui and Noura Aknin, "Study of a microstrip antenna with and without superstrate for terahertz frequency," International Journal of Innovation and Applied Studies, Vol. 2, No.4, pp.369-371, April 2013.

[14] Fan Yang, Juha Virtanen, Atef. Z. Elsherbeni and Leena Ukkonen, "Reconfigurable Sensing Antenna: A Slotted Patch Design with Temperature Sensation," IEEE Antennas and Wireless propagation letters, Vol. 11, 2012.

[15] Lin, C.-C. and H.-R. C. Lin, "A 3-12 GHz UWB planar triangular monopole antenna with ridged ground-plane," Progress In Electromagnetics Research, Vol. 83, pp. 307-321, 2008. 